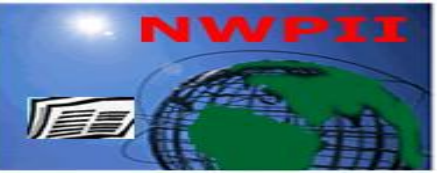

American Journal of Biomedical Sciences

ISSN: 1937-9080

nwpii.com/ajbms

\title{
Erythropoietin Protects Against Exertional Rhabdomyolysis-induced Acute Kidney Injury in Association with Preferential M2 Macrophage Polarization and Hemeoxygenase-1 Activation
}

\author{
Marwa H. Muhammad ${ }^{1}$, Abeer A. Abd Elhameed ${ }^{2}$, Bakr Ahmed ${ }^{3}$ \\ ${ }^{1}$ Department of Medical Physiology, Faculty of Medicine, Benha University, Benha, Qalubyia, Egypt \\ ${ }^{2}$ Department of Clinical Pharmacology and Therapeutics, Faculty of Medicine, Benha University, Qalubyia, Egypt \\ ${ }^{3}$ Department of Pathology, Faculty of Veterinary Medicine, Zagazig University, Zagazig, Sharkia, Egypt \\ *Corresponding Author \\ Marwa Hassan Muhammad. \\ Department of Medical Physiology \\ Faculty of Medicine \\ Benha University \\ Qalubyia \\ Egypt \\ www.fmed.bu.edu.eg \\ Tel: 00201009655692 \\ E-Mail: drmarwa.hassan@yahoo.com
}

Received:09 October 2018; $\mid$ Revised:07 November 2018; | Accepted:16 December 2018

\section{Abstract}

Background: Exertional rhabdomyolysis (ER)-induced acute kidney injury (AKI) is a serious health threat associated with strenuous physical exercise. Erythropoietin (EPO) is a pleiotropic hormone with its immunomodulator function still unclear. We investigated the renoprotective effect of EPO in EXR-induced AKI, with an emphasis on macrophages phenotypic polarization and associated hemeoxygenase1 (HO1) bioactivity.

Methods: Strenuous exercise was applied to rats, either or not preceded by EPO alone or combined with the HO1 enzyme blocker, Zinc protoporphyrins (Zn-PP). Serum levels of creatine phosphokinase, myoglobin, urea nitrogen, creatinine, and carboxyhemoglobin $(\mathrm{COHb}) \%$ were estimated. In addition, we examined the inflammatory cytokines IL10 and TNF a, macrophages phenotypic markers, HO1 expression, and renal pathology.

Results: EPO pre-treatment resulted in significant decreases in blood urea nitrogen, serum creatinine and myoglobin, tubular injury score, and intratubular cast \% in addition to TNF- a decrease, IL10 increase with a preferential switching of macrophage polarization to the reparative M2 phenotype as antiinflammatory effect. Furthermore, EPO pre-treatment was associated with an increase in HO1 protein expression and $\mathrm{COHb} \%$. Such effects were significantly reversed when HO1 activity blocker, Zn-PP, was co-administered. 
Conclusion: Our findings highlight the value of EPO as a prophylactic therapeutic agent against EXRinduced AKI. Additionally, they suggest an underpinning role for HO1 in the EPO-induced modulation of macrophage polarization towards the M2 phenotype.

Keywords: Erythropoietin, M2 macrophage, Heamoxygenase-1, Exertional rhabdomyolysis-induced acute kidney injury

\section{Introduction}

Exertional rhabdomyolysis (EXR) refers to damage and necrosis of skeletal muscle fibers after engaging in intense physical activity $\left.{ }^{[1,} 2\right]$. The condition is common among athletes and military personnel $[1,3,4]$. Acute kidney injury (AKI) is considered one of the most leading complications of rhabdomyolysis. The prevalence of AKI ranges from $10-50 \%{ }^{[5]}$, and has generally been associated with increased renal morbidity and mortality ${ }^{[6]}$.

The EXR-induced damage of skeletal muscle fibers occurs through direct damage of the sarcolemma and/or electrolyte disturbance. Strenuous exercise causes depletion of cell energy, which inhibits the $\mathrm{Na}^{+} / \mathrm{K}^{+}$-ATPase and $\mathrm{Ca}^{2+}$ ATPase pumps. The resultant intracellular accumulation of $\mathrm{Ca}^{2+}$ and $\mathrm{Na}^{+}$induces cell damage through the activation of $\mathrm{Ca}^{2+}$-dependent phospholipases and proteolytic enzymes or osmotic lysis, respectively. Subsequently, intracellular proteins including creatine phosphokinase and myoglobin leak into the circulation ${ }^{[1]}$. Myoglobin is a particular key factor in the pathogenesis of rhabdomyolysis-induced AKI. After glomerular passage, it is reabsorbed and catabolized by the renal tubular cells, which causes them to undergo oxidative stress, apoptosis and vasoconstrictive cytokine responses ${ }^{[5,7]}$.

Current studies propose rhabdomyolysisinduced AKI as an inflammatory disease, in which macrophages play an evitable role ${ }^{[8-11]}$. The kidney's resident macrophages constitute a principal element of the innate immunity and orchestrate both the initiation and resolution of inflammation [12, 13]. They are divided into classically activated macrophages (M1), which secrete pro-inflammatory cytokines and bactericidal reactive oxygen and nitrogen species, and alternatively activated macrophages (M2), which mediate resolution and repair of inflammation ${ }^{[14]}$. A growing body of evidence suggests that accelerated macrophages polarization towards the M2 phenotype is of great value for alleviation and repair of renal EXR-induced AKI ${ }^{[9-11]}$.

Erythropoietin (EPO) is a glycoprotein hormone that is responsible for hemopoiesis, and has been traditionally used for the treatment of anemia. Besides hemopoiesis, recent studies have demonstrated a role for EPO in healing and repair through anti-apoptotic and anti-inflammatory effects $[15,16]$. Furthermore, some studies have identified macrophages as one of the immunetargets for the anti-inflammatory effect of EPO, which inhibits their release of pro-inflammatory cytokines ${ }^{[17-19]}$. Despite this knowledge, the mechanistic basis for the macrophage-targeted antiinflammatory effect of EPO and its therapeutic implications remain elusive.

Hemeoxygenase-1 (HO1) is a rate-limiting enzyme for the degradation of the heme protein into biliverdin, resulting in release of carbon monoxide (CO) and free iron ${ }^{[20]}$. In addition, $\mathrm{HO} 1$ and its $\mathrm{CO}$ byproduct have been previously reported to restore homeostasis in acute and chronic inflammation ${ }^{[21-23]}$, or to promote macrophage switching to the M2 phenotype ${ }^{[22,24]}$.

In the present study, we investigated the potential protective effects of EPO pre-treatment against EXR-induced AKI, with a particular emphasize on the anti-inflammatory role of macrophages. We further looked into the possible involvement of $\mathrm{HO} 1$ in macrophage switching to the anti-inflammatory M2 phenotype.

\section{Materials and Methods}

\subsection{Experimental animals}

Adult male albino rats weighting 200-220 gm were used in the experiment. Animals were purchased from Animal House, Faculty of Veterinary Medicine, Benha University (Egypt), and were housed in cages (three per cage) and maintained on prevailing atmospheric conditions 
and room temperature. Food and water were provided ad libitum. Rats were subjected to an adaptation period of two weeks before experiments. This study was carried out in strict respect to the recommendations of the Guide for the Care and Use of Laboratory Animals of the National Institutes of Health. The protocol was revised and approved by the Committee on the Ethics of Animal Experiments of the Faculty of Medicine, Benha University, Egypt.

\subsection{Drugs and chemicals}

Recombinant human EPO, was purchased from SEDICO Pharmaceutical (Cairo, Egypt). Zinc Protoporphyrin IX (Zn PP), specific inhibitor for HO1, was supplied by Sigma-Aldrich (MO, USA), in the form of powder and dissolved in sodium hydroxide, and then diluted to $1 \mathrm{mg} / \mathrm{ml}$ in normal saline solution.

\subsection{Experimental groups and design}

Rats were randomly divided into the following five groups $(n=6)$ : (i) Control group, in which rats undergone warming-up exercise. (ii) EXR-induced AKI group, in which rats undergone exhaustive exercise training following warming up exercise training. (iii) EPO group, which received EPO at dose of 2000 I.U/ kg, I.P ${ }^{[25]}, 1 / 2 \mathrm{~h}$ before application of exercise. (iv) Zn PP group, which received $\mathrm{Zn}$ PP at a dose of $10 \mathrm{mg} / \mathrm{kg}$, I.P ${ }^{[9]}, 24 \mathrm{~h}$ before application of exercise. (v) Zn PP+ EPO group, which received $10 \mathrm{mg} / \mathrm{kg}$ of $\mathrm{Zn}$ PP and 2000 I.U/ $\mathrm{kg}$ of EPO, I.P, $24 \mathrm{~h}$, and $1 / 2 \mathrm{~h}$, respectively, before application of exercise.

Exercise was executed by Rat treadmill (Panlab/Letica LE8706, Barcelona, Spain). The physiological warming-up exercise was undergone by all experimental groups, and was applied by horizontal running at speed of $17 \mathrm{~cm} / \mathrm{sec}$ for $15 \mathrm{~min}$. Exhaustive exercise was applied by the last four groups, following the warming-up exercise, by running at gradient $10 \%$ for $10 \mathrm{~min}$ at speed of $30 \mathrm{~cm} / \mathrm{sec}$ and then $37 \mathrm{~cm} / \mathrm{sec}$. This followed by running at $44 \mathrm{~cm} / \mathrm{sec}$ for $15 \mathrm{~min}$ and lastly the speed was fixed on $50 \mathrm{~cm} / \mathrm{sec}$ until rats became exhausted. To maintain steady running and ensure same exercise intensity, a shock grid $(0.97 \mathrm{~mA}, 3 \mathrm{~Hz})$, placed at the back of the treadmill, was used to discourage the rats from stopping while the treadmill belt was moving [25]. The rats ran until exhaustion, which is defined as remaining on the shocker plate for more than $10-15$ seconds ${ }^{[26]}$, and time to exhaustion was recorded.

Recovery period of $24 \mathrm{~h}$ was allowed for all groups, and then rats were sacrificed under general anesthesia using intra-peritoneal injection of pentobarbital sodium $(40 \mathrm{mg} / \mathrm{kg})$. Blood samples were collected; a part in a heparinized syringe then placed on ice for carboxyhemoglobin assessment while, the rest in dry clean test tube then left at room temperature to clot. Serum was separated by centrifugation at $3000 \mathrm{rpm}$ for $15 \mathrm{~min}$ and was stored at $-80^{\circ} \mathrm{C}$ for other biochemical analysis.

Prior to the renal dissection, they were perfused with cold phosphate buffered saline (PBS) solution, $\mathrm{pH} 7.4$, containing $0.16 \mathrm{mg} / \mathrm{ml}$ heparin to remove any red blood cells and clots. One kidney was homogenized using a Mixer Mill MM400 (Retsch, Germany) in 5-10 $\mathrm{ml}$ of phosphate buffer per gram tissue then centrifugation for 15 minutes at $4^{\circ} \mathrm{C}$ was performed. The supernatant was removed for biochemical assay. Half of the other kidney was used for real time PCR analysis while, the other half was fixed in $10 \%$ neutral buffered formalin and prepared for histopathology and immunohistochemical analysis.

\subsection{Measurement of biochemical indices related to EXR and AKI}

Measurement of serum creatine phosphokinase (CPK) was performed using the Creatine Kinase Activity Assay Kits (Sigma, MO, USA). The principal of the assay relies on coupled enzyme reaction ${ }^{[27]}$. Measurement of blood urea nitrogen (BUN) and creatinine levels was performed by enzymatic colorimetric method, using commercially available kits (Diamond Diagnostics Company, Cairo, Egypt). Serum myoglobin was measured using a commercial ELISA kit (Abcam, MA, USA) on diluted samples (1:5) according to the manufacturer' $s$ instructions. A standard curve was drawn, and a four-parameter algorithm equation was used to calculate the myoglobin concentrations in each sample. 


\subsection{Cytokine and Carboxyhemoglobin (COHb)} $\%$ Measurement

Renal levels of TNF $a$ and IL10 were assessed by specific rat ELISA kits (Abcam, Cambridge, UK), according to the manufacturer' $\mathrm{s}$ instructions. $\mathrm{COHb} \%$ levels were assessed by spectrophotometer calibrated for rat serum (Jenway, Bibby Scientific Ltd., Staffordshire, UK) ${ }^{[28]}$. Most of the endogenously released $\mathrm{CO}$ is stems from heme degradation, which is a reliable indicator for heme metabolism and the related $\mathrm{HO} 1$ activity ${ }^{[29]}$.

\subsection{RNA extraction and real-time PCR analysis for M1- and M2- exclusive genes}

Based on the exclusive pattern of expression of the M1 and M2 subtypes of macrophages, we utilized Early growth response protein 2 (Egr2) as M2-marker, whereas Cluster of Differentiation 38 (CD38) as M1-marker [30, 31]. Total RNA was isolated from $25 \mathrm{mg}$ tissue using total RNA purification kit (Jena Bioscience Germany). The concentration and purity of the RNA were determined by measuring the absorbance at $260 \mathrm{~nm}$ and $280 \mathrm{~nm}$ by UV spectrophotometer (Optima SP3000, Japan). Pure RNA has an A260/A280 ratio of $1.9-2.3$.

RNA (5 $\mu \mathrm{g})$ was then reversed transcribed using revert aid TM first strand cDNA synthesis kit (Ferments life science, USA) then cDNA was subsequently amplified with the Syber Green PCR Master Kit (Applied Biosystems, USA)

One-step RT-PCR using QuantiTectVR SYBRVR Green RT-PCR master mix kit Cat No./ID: 204243 (Qiagen, GmbH) supplied by clinilab (Egypt), was done in ABI Prism 7900HT (Applied Biosystem, Foster City, CA), QuantiTect SYBR Green RT-PCR Kits contain an optimised, ready-to-use master mix using SYBR Green I. QuantiTect SYBR Green RT-PCR master mix also contains dUTP, enabling pre-treatment with uracilN-glycosylase (UNG) prior to starting PCR, which ensures that any contaminating PCR products do not affect subsequent PCR reactions, the prepared reaction components were done in 96 well PCR plate using Real-time cycler conditions of $50 \mathrm{oC}, 30$ min, (Reverse transcription) $95 \mathrm{oC}, 15 \mathrm{~min}$, (Initial denaturation) followed by 40 cycles of $94 \mathrm{oC}, 30 \mathrm{~s}$, $55 \mathrm{oC}, 1 \mathrm{~min}$ and $72 \mathrm{oC}, 1 \mathrm{~min}$ for Denaturation, Annealing, Extension steps respectively. The housekeeping

Glyceraldehyde-3-phosphate dehydrogenase (GAPDH) gene was used as a reference gene.

Data analysis: According to the RQ manager program ABI prism 7500 the Boxplot software, the data were produced as sigmoid-shaped amplification plots in which the number of cycles is plotted against fluorescence (when using a linear scale). The threshold cycle (CT) served as a tool for calculation of the starting template amount in each sample. Because the relative quantities of the assessed genes are normalised against the relative quantities of the endogenous control GAPDH gene, fold expression changes are calculated using the equation $2^{-\Delta \Delta}$ ct [32].

Rats' primer sequences of both forward and reverse (Operon, Inc., Huntsville, Alabama, Germany) were as follow:

Egr2 forward, CGCCACACCAAGATCCACC, reverse, AGCCCCCAGGACCAGAGG, CD38 forward, TGCAACAAGATTCTTCTTTGGAGCA, reverse, CTCAGGATTTTTCACACACTGAAG, and GAPDH forward, ATGTGTCCGTCGTGGATCTGAC, reverse, AGACAACCTGGTCCTCAGTGTAG.

\subsection{Histopathological examination of renal tissue}

Longitudinal sections of the kidney were fixed immediately in $10 \%$ formalin, embedded in paraffin, sectioned at $4 \mu \mathrm{m}$ thickness and were stained with hematoxylin and eosin (H\&E). Tubule injury was defined by necrotic lysis, tubule dilation, cast formation or sloughing of cellular debris into the tubule lumen and was scored semi-quantitatively as previously described ${ }^{[33]}$. The scoring system was as follows; $0=$ no change in the tubules; $1=<25 \%$ of tubular injury (mild); $2=25 \%$ to $50 \%$ of tubular involvement (moderate); $3=50 \%$ to $75 \%$ of tubules showing characteristic change (severe) and $4=$ more than $75 \%$ of tubular damage (very severe). Five random fields for each kidney slide were examined, and the average score served as the tubular injury score of the kidney tissue sample. To assess intratubular cast formation a semi-quantitative score was calculated in five fields where $0=$ no casts were found in renal tubules; $1=25 \%$ of tubules had casts; $2=50 \%$ of tubules had casts; $3=75 \%$ of tubules contained casts; and $4=$ all tubules contained casts [34]. The tissue sections were observed by a blinded 
pathologist under Olympus microscope system (Olympus, Tokyo, Japan).

\subsection{Immunohistochemical staining of HO1}

Briefly, kidney sections were de-waxed and rehydrated in decreasing concentrations ethanol. After being treated with protein-blocking solution, for endogenous Peroxidase, in $3 \% \mathrm{H}_{2} \mathrm{O} 2$ in methanol for $20 \mathrm{~min}$ at room temperature, the slides were incubated with rabbit polyclonal anti-murine HO1 antibodies (Cayman chemicals, MI, USA) (dilution 1:200) at $4^{\circ} \mathrm{C}$ overnight. Then, the sections were incubated with biotinylated secondary antibody (dilution 1:500) for $30 \mathrm{~min}$ at $37^{\circ} \mathrm{C}$. This was followed by reaction with diaminobenzidine as chromogen and counterstaining with hematoxylin. Images were observed using an Olympus microscope system (Olympus, Tokyo, Japan).The HO1 positive immune-reactive cells were quantified by counting in 10 images of high-power magnification $\times 400$ per section for each group using Image-Pro Plus program version 6.0 (Media Cybernetics Inc., Bethesda, Maryland, USA) in the Pathology Department, Faculty of Medicine, Benha University, Egypt. The data were expressed as the percentage of $\mathrm{HO} 1$ positive cells in the total examined area as observed by a pathologist in a blinded manner on coded slides.

\section{Statistical analysis}

All data were analyzed using the program Statistical Package for Social Sciences (SPSS) version 19 (SPSS Inc., Chicago, Illinois, USA). Data are presented as the mean \pm standard deviation (SD). Comparisons of all parameters among the study groups were performed by using one-way analysis of variance (ANOVA) with LSD post-hoc to compensate for multiple comparisons. $\mathrm{P}$ value $<0.05$ was considered statistically significant.

\section{Results}

Table 1: Physical, biochemical, inflammatory cytokines parameters, and COHb \% in experimental groups

\begin{tabular}{|c|c|c|c|c|c|}
\hline & $\begin{array}{c}\text { Control } \\
\text { group }\end{array}$ & $\begin{array}{c}\text { EXR-induced } \\
\text { AKI group }\end{array}$ & $\begin{array}{c}\text { EPO } \\
\text { group }\end{array}$ & $\begin{array}{c}\text { Zn PP } \\
\text { group }\end{array}$ & $\begin{array}{c}\text { Zn PP+ EPO } \\
\text { group }\end{array}$ \\
\hline $\begin{array}{c}\text { Time to } \\
\text { exhaustion (min) }\end{array}$ & - & $178 \pm 16$ & $256 \pm 32^{\#}$ & $103 \pm 19^{\#}$ & $185 \pm 34^{\$}$ \\
\hline $\mathrm{CPK}(\mathrm{U} / \mathrm{L})$ & $134 \pm 25$ & $5644 \pm 234^{*}$ & $5551 \pm 303^{*}$ & $6912 \pm 409^{*}$ & $5605 \pm 156^{*}$ \\
\hline $\begin{array}{c}\mathrm{Myoglobin} \\
(\mathrm{ng} / \mathrm{ml})\end{array}$ & $22 \pm 5$ & $278 \pm 64^{*}$ & $166 \pm 41^{*}$ & $306 \pm 72^{*}$ & $266 \pm 34^{*}$ \\
\hline $\mathrm{BUN}(\mathrm{mg} / \mathrm{dl})$ & $9.5 \pm 1.1$ & $38.1 \pm 1.3^{*}$ & $11.1 \pm 1.1^{\#}$ & $43 \pm 1.9^{* \#}$ & $37 \pm 1.8^{* \$}$ \\
\hline $\mathrm{sCr}(\mathrm{mg} / \mathrm{dl})$ & $0.72 \pm 0.19$ & $4.11 \pm 0.4^{*}$ & $0.98 \pm 0.11^{* \#}$ & $5.38 \pm 0.7^{* \#}$ & $3.7 \pm 0.67^{* \$}$ \\
\hline $\mathrm{TNF} \alpha(\mathrm{pg} / \mathrm{ml})$ & $7.35 \pm 0.94$ & $41.3 \pm 2.9^{*}$ & $12.28 \pm 3.3^{* \#}$ & $56.65 \pm 5.9^{* \#}$ & $39.55 \pm 2.8^{* \$}$ \\
\hline $\mathrm{IL} 10(\mathrm{pg} / \mathrm{ml})$ & $276 \pm 30$ & $121 \pm 9$ & $773 \pm 58^{* \#}$ & $103 \pm 5^{* \#}$ & $385 \pm 25^{\$}$ \\
\hline $\mathrm{COHb}(\%)$ & $0.26 \pm 0.04$ & $0.55 \pm 0.04^{*}$ & $0.91 \pm 0.04^{* \#}$ & $0.21 \pm 0.06^{* \#}$ & $0.23 \pm 0.03^{\$}$ \\
\hline
\end{tabular}

Data are expressed as mean \pm standard deviation $\mathrm{SD} ;(\mathrm{n}=6) ;{ }^{*} \mathrm{p}<0.05$ significant difference compared with the control group while ${ }^{*} \mathrm{p}<0.05$ significant difference compared with the EXR-induced AKI group and ${ }^{\$} \mathrm{P}<0.05$ significant difference compared with the EPO group. The carboxyhemoglobin expressed by log transformation for $\mathrm{COHb}$. EXR-induced $\mathrm{AKI}$; exertional rhabdomyolysis-induced acute kidney injury, EPO; erythropoietin, Zn PP; Zinc protoporphyrins, CPK; Creatine phosphokinase, BUN; blood urea nitrogen, sCr; serum creatinine, TNF $\alpha$; tumor necrosis factor $\alpha$, IL10; interleukins 10, COHb; carboxyhemoglobin. 

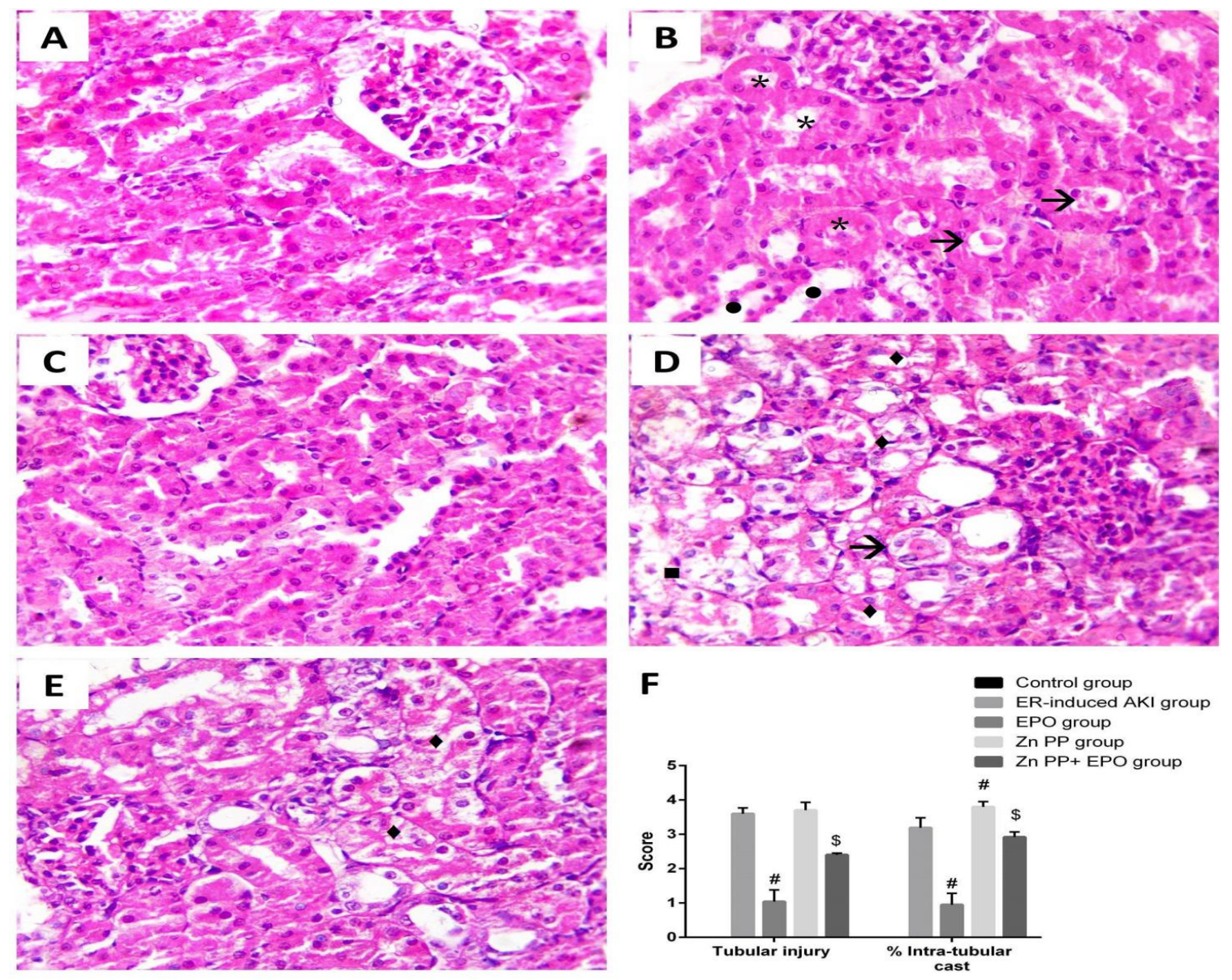

Figure 1: Histopathological picture of H\&E-stained sections and scores of renal damage

(A); Normal kidney architecture of the control group. (B) EXR-induced AKI showing extensive cloudy swelling of tubular epithelial cells $(*)$, tubular dilatation $(\bullet)$, and cast formation $(\rightarrow)$ ). (C) A nearly normal architecture with EPO group. (D) Marked renal damage with hydropic degeneration ( $\bullet$ ), cast formation $(\rightarrow)$, and necrosis (-) as induced by pre-treatment with Zn PP alone in Zn PP group. (E) Tubular hydropic degenerative changes ( $\downarrow)$ in the ZN PP + EPO group. (F) Tubular injury score and intra-tubular cast formation $\%$ for all experimental groups; data expressed as mean \pm standard deviation $\mathrm{SD}$; $(\mathrm{n}=6) ;{ }^{\#} \mathrm{P}<0.05$ significant difference compared with EXR-induced AKI group and ${ }^{\$} \mathrm{P}<0.05$ significant difference compared with EPO group. Magnification $=x 400$. EXR-induced AKI; exertional rhabdomyolysis induced acute kidney injury, EPO; erythropoietin, and Zn PP; Zinc protoporphyrins.

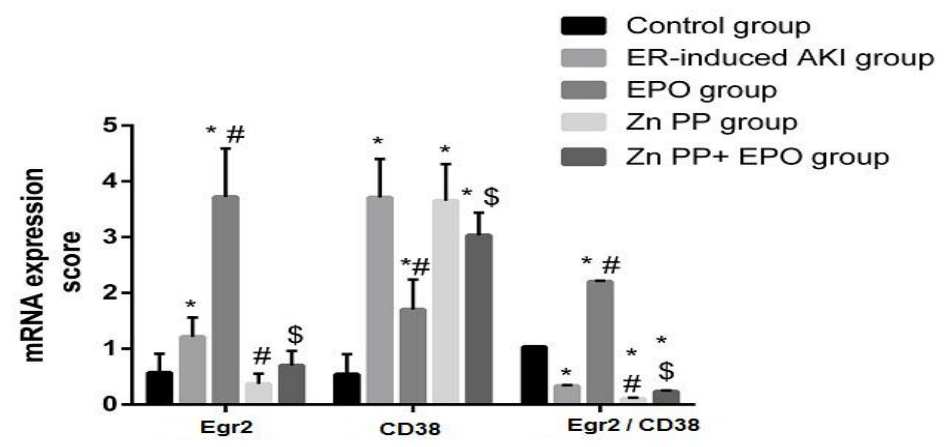

Figure 2: Effect of EPO pre-treatment on Egr2 and CD38 mRNA expression and their ratio 
Data expressed as mean \pm standard deviation $\mathrm{SD} ;(\mathrm{n}=6) .{ }^{*} \mathrm{P}<0.05$ significant difference compared with the control group, ${ }^{\#} \mathrm{P}<0.05$ significant difference compared with EXR-induced AKI group and ${ }^{\mathrm{S}} \mathrm{P}<0.05$ significant difference compared with EPO-treated group. EXR-induced AKI; exertional rhabdomyolysis induced acute kidney injury, EPO; erythropoietin, Zn PP; Zinc protoporphyrins, Egr2; Early growth response protein 2, CD38; Cluster of differentiation 38
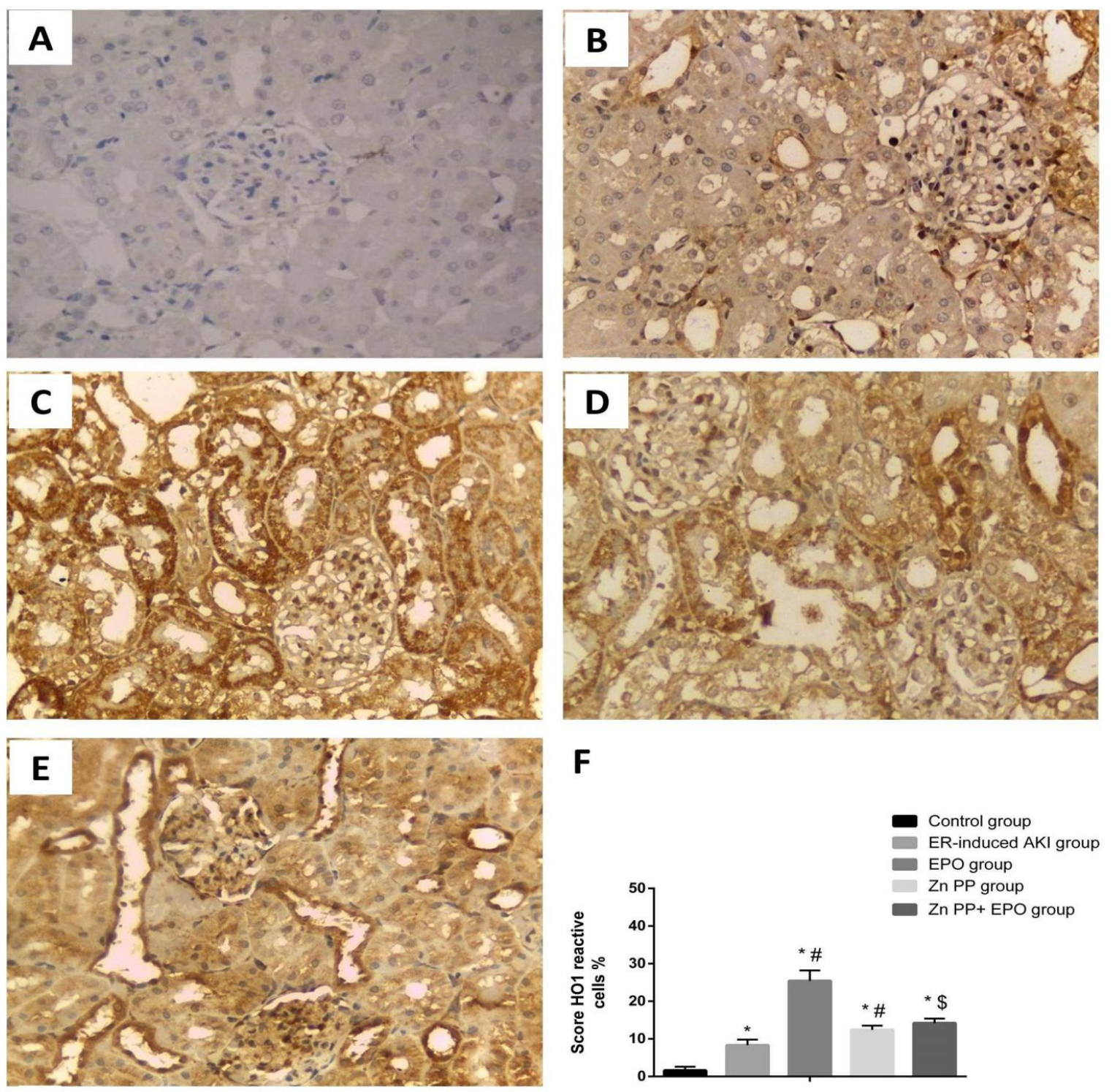

Figure 3: Immunohistochemical staining of renal tissue for $\mathrm{HO1}$ expression and \% of immunoreactive cells score

(A); Control group, (B); EXR-induced AKI group, (C); EPO group, (D); Zn PP group, (E); Zn PP + EPO group and $(\mathrm{F}) ; \%$ of immunoreactive cells score; data expressed as mean \pm standard deviation SD; $(\mathrm{n}=6) ;{ }^{*} \mathrm{P}<0.05$ significant difference compared with the control group, ${ }^{\#} \mathrm{P}<0.05$ significant difference compared with EXR-induced AKI group and ${ }^{{ }^{\$}} \mathrm{P}<0.05$ significant difference compared with EPO group. Magnification $=x 400$. EXR-induced AKI; exertional rhabdomyolysis induced acute kidney injury, EPO; erythropoietin, and Zn PP; Zinc protoporphyrins. 


\subsection{Effect of EPO pre-treatment on Time to exhaustion (Table 1)}

All experimental rats appeared physically sound, dynamic, and alert before the application of before the application of exhaustive exercise to induce ER and the subsequent AKI. After the intensive exercise was applied to the EXR-induced AKI group, rats showed signs of fatigue and suffered a stasis accompanied by a shorter time to exhaustion compared to the control group $(\mathrm{P}<0.05)$. Zn PP group showed the same signs of exhaustion, in addition to sub-conjunctival hemorrhage, and early exhausted than other groups with the significant least time to exhaustion $(\mathrm{P}<0.05)$. Conversely, EPO group tolerated better to the exhaustive exercise, showed higher tolerance; scoring the longest time to exhaustion among the groups $(\mathrm{P}<0.05)$. On the other hand, when $\mathrm{Zn} \mathrm{PP}$ preceded EPO administration, such effects were reversed and Time to exhaustion was significantly decreased versus EPO group $(\mathrm{P}<0.05)$.

\subsection{Effect of EPO pre-treatment on renal function indices (Table 1)}

Compared to the control group, serum myoglobin and CPK levels were significantly increased in EXR-induced AKI, EPO, Zn PP and Zn $\mathrm{PP}+\mathrm{EPO}$ groups $(\mathrm{P}<0.05)$. The differences of CPK levels among these groups were statistically nonsignificant, except for the Zn PP group that showed significantly higher levels compared to the EPO group $(\mathrm{P}<0.05)$.

Concerning serum levels of BUN and $\mathrm{Cr}$, they were significantly elevated in the EXR-induced AKI group as compared to the control one $(\mathrm{P}<$ 0.05). Moreover, Zn PP group exhibited significantly higher levels of BUN and $\mathrm{Cr}$ than those in other groups $(\mathrm{P}<0.05)$. On the contrary, EPO group exhibited significant decreases in serum BUN and $\mathrm{Cr}$ levels when compared to EXRinduced AKI group. Meanwhile, when $\mathrm{Zn} \mathrm{PP}$ preceded EPO administration, it significantly reversed EPO effect $(\mathrm{P}<0.05)$.

\subsection{Effect of EPO pre-treatment on renal architecture (Figure 1)}

The biochemical alterations were simultaneously confirmed by changes in the renal tissue architecture. Compared to the normal renal structure shown for the control group (Fig 1A), histopathological examination of H\&E-stained tissue sections form the EXR-induced AKI group showed parenchymal changes including cloudy swelling of tubular epithelial cells, tubular dilatation and some cast formation (Fig 1B). These histopathological lesions were largely ameliorated in the EPO group, which showed a nearly normal renal architecture (Fig 1C). Tubular injury score and intratubular cast $\%$ were significantly decreased versus EXR-induced AKI group (P < 0.05) (Fig 1F). On the contrary, when $\mathrm{Zn}$ PP preceded EPO administration group, it diminished the effect of EPO, as evident by lesions of hydropic changes, necrosis, and cast formation, as well as the significant increase in tubular injury score and intratubular cast \% versus EPO group $(\mathrm{P}<0.05)$ (Fig. $1 \mathrm{E}$ and $1 \mathrm{~F})$. Furthermore, $\mathrm{Zn}$ PP group showed marked renal damage and demonstrated comparable tubular injury score and intra-tubular cast $\%$ to the EXR-induced AKI group $(\mathrm{P}<0.05)$ (Fig. $1 \mathrm{D}$ and $1 \mathrm{~F})$.

\subsection{Effect of EPO pre-treatment on Egr2 and CD38 mRNA expressions (Figure 2)}

It was observed that Egr2 mRNA expression was significantly upregulated in EPO group compared to the EXR-induced AKI group ( $\mathrm{P}<$ $0.05)$. This effect was significantly attenuated when EPO was preceded by Zn PP $(\mathrm{P}<0.05)$. Concerning renal CD38 mRNA expression, it was significantly upregulated in EXR-induced AKI group compared to the control group $(\mathrm{P}<0.05)$. Moreover, the EPO group showed significant downregulation in its expression when compared to EXR-induced AKI group $(\mathrm{P}<0.05)$. However, $\mathrm{Zn} \mathrm{PP}$ abolished the effect of EPO and caused significant upregulation in renal CD38 mRNA expression compared to EXRinduced AKI group $(\mathrm{P}<0.05)$.

Afterwards, we calculated the M2 (Egr2) / M1 (CD38) ratio. The control group showed a balance between M1 and M2 macrophages expression. A decreased $\mathrm{M} 2 / \mathrm{M} 1$ ratio was observed in EXRinduced AKI group, while it was reversed with EPO pre-treatment. On the other hand, blocking HO1 activity in $\mathrm{Zn} \mathrm{PP}$ and $\mathrm{Zn} \mathrm{PP}+\mathrm{EPO}$ groups resulted in a significant decrease in $\mathrm{M} 2 / \mathrm{M} 1$ ratio when compared to the EPO group $(\mathrm{P}<0.05)$. 


\subsection{Effect of EPO pre-treatment on inflammatory cytokines (Table 1)}

Levels of TNF a were significantly higher in the EXR-induced AKI group compared to the control $(\mathrm{P}<0.05)$. Furthermore, this cytokine showed significantly downregulated in the EPO group compared to EXR-induced AKI group ( $\mathrm{P}<$ 0.05). However, such effect was significantly reversed when EPO was preceded by $\mathrm{Zn}$ PP administration $(\mathrm{P}<0.05)$. Renal TNF a in Zn PP group was significantly higher than those in other groups $(\mathrm{P}<0.05)$.

Renal levels of the anti-inflammatory cytokine IL10 were significantly higher in the EPO group compared to EXR-induced AKI group $(\mathrm{P}<0.05)$. By contrast, Zn PP intervention in Zn PP and Zn $\mathrm{PP}+\mathrm{EPO}$ groups resulted in significant decrease of the cytokine production compared with the EPO group $(\mathrm{P}<0.05)$. Moreover, it was the least in $\mathrm{Zn} \mathrm{PP}$ group than in other groups $(\mathrm{P}<0.05)$.

\subsection{Effect of EPO pre-treatment on HO1 expression (Figure 3) and $\mathrm{COHb \%}$ (Table 1)}

Immunohistochemical analysis of renal expression of $\mathrm{HO} 1$ protein showed faint or no immunoreactive cells in renal tubules in the control group (Fig 3A). In EXR-induced AKI group some renal tubules show considerable significant staining (Fig 3B) and was associated with an increase in $\mathrm{COHb} \%$, an indicator of heme degradation and endogenous $\mathrm{CO}$ release by $\mathrm{HO} 1$ activity when compared to the control group (Table 1). EPO group (Fig. 3C) showed highest HO1 expression and $\mathrm{COHb} \%$ with respect to other groups $(\mathrm{P}<$ 0.05). Surprisingly, we observed that $\mathrm{Zn} P P$ intervention in $\mathrm{Zn} \mathrm{PP}$ and $\mathrm{Zn} \mathrm{PP}+\mathrm{EPO}$ groups (Fig $3 \mathrm{D}$ and $3 \mathrm{E}$ ) showed significant much renal tubules staining $(\mathrm{P}<0.05)$ as compared to EXR-induced AKI and control groups (Fig 3F) but with decreased $\mathrm{COHb} \%$. Moreover we observed in $\mathrm{Zn}$ PP group, $\mathrm{COHb} \%$ was significantly the least among those in other groups $(\mathrm{P}<0.05)$.

\section{Discussion}

AKI is one of the leading complications of ER and can cause serious renal complications. In the present study, we demonstrated the protective effect of EPO pre-treatment against the condition in a rat model of ER. In our model, rats exposed to exhaustive exercise training exhibited significant increase in serum CPK, a sensitive degradation product of myocytes that confirms the occurrence of ER. Acute strenuous exercise causes damage to skeletal muscles fibers either through direct damage of the cell membrane or hindrance of energymediated electrolyte pumps. Following muscular injury, subsequent release of tremendous amount of the intracellular CPK and myoglobin occurs ${ }^{[1]}$. The latter caused a deterioration of renal functions, as indicated by the significant increase in BUN and sCr levels [35], and extensive tubular damage, dilatation and cast formation as evident by histological analysis. These findings are in agreement with those previously described by Lin et al. ${ }^{[25]}$, and further confirm the validity of their model to study EXR-induced AKI.

With regard to macrophage function, oxidative damage, ischemia and tubular cell death, serve as an important inducer of recruitment of innate immune cells. The outsets of AKI are typically followed by a rapid and abundant renal influx of blood monocytes that subsequently differentiate into macrophages ${ }^{[36}$, ${ }^{37}$ ]. The AKI-associated innate cytokine responses direct these resident macrophages to switch to the pro-inflammatory M1 phenotype ${ }^{[38]}$. The latter is known to differentially express CD38 ${ }^{[30]}$, as well as high levels of the pro-inflammatory cytokine TNF a [13]. Indeed, both markers were differentially expressed in the EXR-induced AKI group compared to the control, indicating a role for M1 macrophages in the development of the disease.

Pretreatment with EPO has improved renal function and ameliorated the inflammatory responses associated with EXR-induced AKI. This is consistent with a vast body of studies that described the pleiotropic effects of EPO for improved survival of renal tubular cells, increased renal and glomerular blood flow, improved endothelial regeneration and function, and reduced inflammation ${ }^{[39]}$. Although these protective effects can plausibly be linked to the interaction of EPO with local receptors, which are abundantly expressed on renal tubular cells and endothelial cells ${ }^{[40]}$, our study rather focused on the potential contributing role of macrophages in protection against AKI. Previous studies have proposed macrophages as a new target in rhabdomyolysis 
induced AKI $[9,26,41]$. As compared to the EXRinduced AKI group, the EPO group showed significant increase in renal IL10 and Egr2 mRNA expression, indicative of M2 switching [30]. Additionally, by calculating Egr2/CD38 ratio, we found M2 dominance in the contrary of M1 dominance in EXR-induced AKI.

This EPO-enhancing effect on M2 polarization in rhabdomyolysis induced AKI in rats is consistent with the findings of Wang et al. ${ }^{[42]}$. Moreover, Rubio-Navarro and his colleagues have studied the macrophage phenotypes associated with rhabdomyolysis induced AKI and demonstrated that myoglobin promotes an early inflammatory M1 response and differentiation towards M2 with M2 dominance but at day 7 after rhabdomyolysis induction ${ }^{[41]}$. Herein the M2 dominance occurred earlier with EPO preconditioning; 24h after rhabdomyolysis induction, which reflects an EPOmediated acceleration of macrophages switching from M1 to M2 phenotype.

The EPO regulation of the polarization dynamics of renal macrophages is traced back to inhibition of NF- K B P65 subunit activation and subsequent activation of target gene expression [17] under inflammatory conditions [43, 44]. However, although our study of EXR-induced AKI does not tackle the molecular basis for the favorable EPOinduced M2 macrophage polarization, we explored the possible association of $\mathrm{HO} 1$ activity which might mediate macrophage polarization towards the M2 phenotype ${ }^{[24,43]}$. In our study, EPO-treatment was associated with higher $\mathrm{HO} 1$ expression and activity. On the contrary, co-administration $\mathrm{Zn}$ PP as an HO1-enzyme inhibitor has significantly lowered HO1 activity and weakened M2 switching capacity compared to the EPO group. In addition, the effect of EPO on renal architecture and cytokine responses was similarly reversed under the inhibitor's effect. These findings support the notion that $\mathrm{HO} 1$ activity might mediate the renoprotective effect of EPO in AKI.

In this regard, previous studies demonstrated the stimulating effect of EPO on HO1 expression in hepatocytes after ischemia/reperfusion injury ${ }^{[45]}$, neurons [46], astrocytes [47] and in monocyte of patient under hemodialysis ${ }^{[48]}$. Moreover, the stimulatory effect of EPO on renal HO1 expression has been described in vivo and in vitro ${ }^{[49]}$, in addition to the stimulatory effect of $\mathrm{HO} 1$ on differentiation of M2 macrophages in models of protection against obesity-induced inflammation ${ }^{[50]}$, diabetic cardiomypathy ${ }^{[51]}$, diabetic gastroparesis ${ }^{[52]}$, colonic inflammation ${ }^{[53]}$ and atherosclerosis ${ }^{[54]}$. To our knowledge, our study is the first to suggest the same effect of EPO on HO1 expression in the kidney, unraveling an important physiological mechanism with therapeutic potential.

Surprisingly, we have noticed a non-significant change of myoglobin and CPK levels in EPO group, leading us to suggest that EPO has no direct protective effect on muscles, and the improved general health of EPO group was due to renal protective outcome. Conflicting results regarding identification and functionality of the EPO receptors in muscular tissue and across species were reported $[55,56]$. We have also noticed that with respect to all other groups, Zn PP group exhibited severe renal damage; the least time to exhaustion, the highest levels of BUN, serum Cr, tubular injury score and intra-tubular cast $\%$ in addition to TNF a and CD38 mRNA expression, as well as a decrease in $\mathrm{COHb} \%$. Taken together, these findings suggest that the $\mathrm{Zn}$ PP blockage of HO1 activity aggravated renal injury and inflammation and have shed light on the crucial role of $\mathrm{HO} 1$ in EPO-conferred protection against EXR-induced AKI.

Unpredictably, the $\mathrm{Zn}$ PP group exhibited significant increase in renal $\mathrm{HO} 1$ protein expression, although it was associated with the significant decrease in $\mathrm{COHb} \%$ versus control and EXRinduced AKI groups. This dichotomy could be explained by a negative feedback circuit that inhibiting the HO1 activity leads to subsequent compensatory activation of $\mathrm{HO} 1$ expression, although the molecular mechanisms underlying this effect remain unclear.

Finally, renal $\mathrm{HO} 1$ protein expression and $\mathrm{COHb} \%$ were significantly increased in EXRinduced AKI group versus the control. The increasing $\mathrm{HO} 1$ expression in the EXR-induced AKI group gives rise to the importance of heme as a physiological inducer for $\mathrm{HO} 1$ expression and activity. This goes hands with the findings of Nath and his team, who initially reported HO1 expression as a rapid and protective reaction in rhabdomyolysis [57]. However this shock-response appears to be insufficient to protect the kidneys, due to associated 
renal dysfunctions, being the pool of free heme is radically increased following rhabdomyolysis caused by dissociation from myoglobin and release of heme containing proteins and enzymes as cytochrome from damaged tubular cells ${ }^{[41]}$.

\section{Conclusion}

To our knowledge, this study is the first to demonstrate the renoprotective effects against EXRinduced AKI by enhancing macrophages switching towards the anti-inflammatory M2 phenotype. In addition, the study provides an early evidence for the possible involvement the HO1 activation in the preferential M2 macrophage polarization under EPO treatment, which requires further molecular investigation.

\section{Acknowledgements}

We gratefully thank the technical and administrative staff at the physiology and pharmacology departments, Faculty of Medicine, Benha University and the pathology department, Faculty of Veterinary Medicine, Zagazig University for their assistance and support.

\section{References}

1 Scalco RS, Snoeck M, Quinlivan R, Treves S, Laforet P, Jungbluth H, Voermans NC. Exertional rhabdomyolysis: physiological response or manifestation of an underlying myopathy? BMJ Open Sport Exerc Med 2016; 2(1): e000151 DOI: $10.1136 / \mathrm{bmjsem}-2016-$ $\underline{000151}$

2 Kruger K, Frost S, Most E, Volker K, Pallauf J, Mooren FC. Exercise affects tissue lymphocyte apoptosis via redox-sensitive and Fasdependent signaling pathways. Am J Physiol Regul Integr Comp Physiol 2009; 296(5): R1518-1527

DOI: $\underline{\text { 10.1152/ajpregu.90994.2008 }}$

3 Malik, G. H. (1998). Rhabdomyolysis and myoglobin-induced acute renal failure. Saudi Journal of Kidney Diseases and Transplantation, $\quad 9(3), \quad 273$. http://www.sjkdt.org/text.asp?1998/9/3/273/39 $\underline{270}$
4 Efstratiadis G, Voulgaridou A, Nikiforou D, Kyventidis A, Kourkouni E, Vergoulas G. Rhabdomyolysis updated. Hippokratia 2007; 11(3): 129-137 [PMID: 19582207 PMCID: PMC2658796]

5 Bosch X, Poch E, Grau JM. Rhabdomyolysis and acute kidney injury. N Engl J Med 2009; 361(1): 62-72 DOI: 10.1056/NEJMra0801327

6 Bagley, W. H., Yang, H., \& Shah, K. H. (2007). Rhabdomyolysis. Internal and emergency medicine, 2(3), 210-218. https://link.springer.com/article/10.1007\%2Fs1 $\underline{1739}$

7 Kim JH, Lee SS, Jung MH, Yeo HD, Kim HJ, Yang JI, Roh GS, Chang SH, Park DJ. Nacetylcysteine attenuates glycerol-induced acute kidney injury by regulating MAPKs and Bcl-2 family proteins. Nephrol Dial Transplant 2010; 25(5): 1435-1443 DOI: 10.1093/ndt/gfp659

8 Kim JH, Lee DW, Jung MH, Cho HS, Jeon DH, Chang SH, Park DJ. Macrophage depletion ameliorates glycerol-induced acute kidney injury in mice. Nephron Exp Nephrol 2014; 128(1-2): 21-29 DOI: $\underline{10.1159 / 000365851}$

9 Belliere J, Casemayou A, Ducasse L, ZakaroffGirard A, Martins F, Iacovoni JS, GuilbeauFrugier C, Buffin-Meyer B, Pipy B, Chauveau D, Schanstra JP, Bascands JL. Specific macrophage subtypes influence the progression of rhabdomyolysis-induced kidney injury. $\boldsymbol{J}$ Am Soc Nephrol 2015; 26(6): 1363-1377 DOI: 10.1681/ASN.2014040320

10 Homsi E, Janino P, Amano M, Saraiva Camara NO. Endogenous hepatocyte growth factor attenuates inflammatory response in glycerolinduced acute kidney injury. Am J Nephrol 2009; 29(4): 283-291 DOI: $\underline{10.1159 / 000159275}$

11 Geng Y, Zhang L, Fu B, Zhang J, Hong Q, Hu $\mathrm{J}$, Li D, Luo C, Cui S, Zhu F, Chen X. Mesenchymal stem cells ameliorate rhabdomyolysis-induced acute kidney injury via the activation of M2 macrophages. Stem Cell Res Ther 2014; 5(3): 80 DOI: 10.1186/scrt469

12 Stamatiades EG, Tremblay ME, Bohm M, Crozet L, Bisht K, Kao D, Coelho C, Fan X, 
Yewdell WT, Davidson A, Heeger PS, Diebold $\mathrm{S}$, Nimmerjahn F, Geissmann F. Immune Monitoring of Trans-endothelial Transport by Kidney-Resident Macrophages. Cell 2016; 166(4): 991-1003 DOI: 10.1016/j.cell.2016.06.058

13 Boyle JJ, Harrington HA, Piper E, Elderfield K, Stark J, Landis RC, Haskard DO. Coronary intraplaque hemorrhage evokes a novel atheroprotective macrophage phenotype. $\mathbf{A m ~} \mathbf{J}$ Pathol 2009; 174(3): 1097-1108 DOI: $\underline{\text { 10.2353/ajpath.2009.080431 }}$

14 Duffield JS. Macrophages and immunologic inflammation of the kidney. Semin Nephrol 2010; 30(3): 234-254 DOI: 10.1016/j.semnephrol.2010.03.003

15 Maiese K, Li F, Chong ZZ. New avenues of exploration for erythropoietin. JAMA 2005; 293(1): 90-95 DOI: 10.1001/jama.293.1.90

16 Ghezzi P, Bernaudin M, Bianchi R, Blomgren K, Brines M, Campana W, Cavaletti G, Cerami A, Chopp M, Coleman T, Digicaylioglu M, Ehrenreich H, Erbayraktar S, Erbayraktar Z, Gassmann M, Genc S, Gokmen N, Grasso G, Juul S, Lipton SA, Hand CC, Latini R, Lauria G, Leist M, Newton SS, Petit E, Probert L, Sfacteria A, Siren AL, Talan M, Thiemermann C, Westenbrink D, Yaqoob M, Zhu C. Erythropoietin: not just about erythropoiesis. Lancet 2010; 375(9732): 2142 DOI: 10.1016/S0140-6736(10)60992-0

17 Nairz M, Schroll A, Moschen AR, Sonnweber T, Theurl M, Theurl I, Taub N, Jamnig C, Neurauter D, Huber LA, Tilg H, Moser PL, Weiss G. Erythropoietin contrastingly affects bacterial infection and experimental colitis by inhibiting nuclear factor-kappaB-inducible immune pathways. Immunity 2011; 34(1): 6174 DOI: $10.1016 /$ j.immuni.2011.01.002

18 Cravedi P, Manrique J, Hanlon KE, ReidAdam J, Brody J, Prathuangsuk P, Mehrotra A, Heeger PS. Immunosuppressive effects of erythropoietin on human alloreactive T cells. $\boldsymbol{J}$ Am Soc Nephrol 2014; 25(9): 2003-2015 DOI: $\underline{10.1681 / \text { ASN.2013090945 }}$

19 Wiedenmann T, Ehrhardt S, Cerny D, Hildebrand D, Klein S, Heeg K, Kubatzky KF. Erythropoietin acts as an anti-inflammatory signal on murine mast cells. Mol Immunol
2015; 65(1): 68-76 DOI: 10.1016/j.molimm.2015.01.011

20 He XH, Yan XT, Wang YL, Wang CY, Zhang ZZ, Zhan J. Transduced PEP-1-heme oxygenase-1 fusion protein protects against intestinal ischemia/reperfusion injury. $\boldsymbol{J}$ Surg Res 2014; 187(1): 77-84 DOI: 10.1016/j.jss.2013.09.040

21 Alam J, Stewart D, Touchard C, Boinapally S, Choi AM, Cook JL. Nrf2, a Cap'n'Collar transcription factor, regulates induction of the heme oxygenase-1 gene. J Biol Chem 1999; 274(37): 26071-26078 [PMID: 10473555]

22 Lee TS, Chau LY. Heme oxygenase-1 mediates the anti-inflammatory effect of interleukin-10 in mice. Nat Med 2002; 8(3): 240-246 DOI: 10.1038/nm0302-240

23 Ndisang JF. Role of heme oxygenase in inflammation, insulin-signalling, diabetes and obesity. Mediators Inflamm 2010; 2010: 359732 DOI: $10.1155 / 2010 / 359732$

24 Alcaraz MJ, Fernandez P, Guillen MI. Antiinflammatory actions of the heme oxygenase-1 pathway. Curr Pharm Des 2003; 9(30): 25412551 [PMID: 14529552]

25 Lin X, Qu S, Hu M, Jiang C. Protective effect of erythropoietin on renal injury induced by acute exhaustive exercise in the rat. Int $\boldsymbol{J}$ Sports Med 2010; 31(12): 847-853 [PMID: 21072740 DOI: $10.1055 / \mathrm{s}-0030-1265205]$

26 Tadaishi M, Miura S, Kai Y, Kano Y, Oishi Y, Ezaki O. Skeletal muscle-specific expression of PGC-1alpha-b, an exercise-responsive isoform, increases exercise capacity and peak oxygen uptake. PLoS One 2011; 6(12): e28290 DOI: 10.1371 journal.pone.0028290

27 Simpson, J. A. (1975). Clinical chemistry. Conversion scales for si units with adult normal reference values. Journal of Neurology, Neurosurgery, and Psychiatry, 38(11), 1142. PMCID: PMC492178

28 Rodkey FL, Hill TA, Pitts LL, Robertson RF. Spectrophotometric measurement of carboxyhemoglobin and methemoglobin in blood. Clin Chem 1979; 25(8): 1388-1393 [PMID: 455674]

29 Fazekas AS, Wewalka M, Zauner C, Funk GC. Carboxyhemoglobin levels in medical intensive care patients: a retrospective, 
observational study. Crit Care 2012; 16(1): R6 DOI: $10.1186 / \mathrm{cc} 11138$

30 Jablonski KA, Amici SA, Webb LM, RuizRosado Jde D, Popovich PG, Partida-Sanchez S, Guerau-de-Arellano M. Novel Markers to Delineate Murine M1 and M2 Macrophages. PLoS One 2015; 10(12): e0145342 DOI: 10.1371/journal.pone.0145342

31 Gregory KJ, Morin SM, Schneider SS. Regulation of early growth response 2 expression by secreted frizzled related protein 1. BMC Cancer 2017; 17(1): 473 DOI: 10.1186/s12885-017-3426-y

32 Livak KJ, Schmittgen TD. Analysis of relative gene expression data using real-time quantitative PCR and the 2(-Delta Delta C(T)) Method. Methods 2001; 25(4): 402-408 DOI: 10.1006/meth.2001.1262

33 Yang CW, Li C, Jung JY, Shin SJ, Choi BS, Lim SW, Sun BK, Kim YS, Kim J, Chang YS, Bang BK. Preconditioning with erythropoietin protects against subsequent ischemiareperfusion injury in rat kidney. $\boldsymbol{F A S E B} \boldsymbol{J}$ 2003; 17(12): 1754-1755 [PMID: 12958199 DOI: $10.1096 /$ fj.02-1191fje]

34 Coombes, J.D., et al., Rapamycin worsens renal function and intratubular cast formation in protein overload nephropathy. Kidney Int, 2005. 68(6): p. 2599-607.

35 Gowda S, Desai PB, Kulkarni SS, Hull VV, Math AA, Vernekar SN. Markers of renal function tests. $\boldsymbol{N} \boldsymbol{A m} \boldsymbol{J}$ Med Sci 2010; 2(4): $170-173$

36 Jang HR, Rabb H. Immune cells in experimental acute kidney injury. Nat Rev Nephrol 2015; 11(2): 88-101 DOI: 10.1038/nrneph.2014.180

37 Williams TM, Little MH, Ricardo SD. Macrophages in renal development, injury, and repair. Semin Nephrol 2010; 30(3): 255-267 DOI: 10.1016/j.semnephrol.2010.03.011

38 Fahling M, Mathia S, Paliege A, Koesters R, Mrowka R, Peters H, Persson PB, Neumayer HH, Bachmann S, Rosenberger C. Tubular von Hippel-Lindau knockout protects against rhabdomyolysis-induced AKI. $\boldsymbol{J}$ Am Soc Nephrol 2013; 24(11): 1806-1819 DOI: $\underline{10.1681 / A S N .2013030281}$
39 Moore E, Bellomo R. Erythropoietin (EPO) in acute kidney injury. Ann Intensive Care 2011; 1(1): 3 DOI: $10.1186 / 2110-5820-1-3$

40 Westenfelder C, Biddle DL, Baranowski RL. Human, rat, and mouse kidney cells express functional erythropoietin receptors. Kidney Int 1999; 55(3): 808-820 DOI: 10.1046/j.15231755.1999.055003808.x

41 Rubio-Navarro A, Carril M, Padro D, Guerrero-Hue M, Tarin C, Samaniego R, Cannata P, Cano A, Villalobos JM, Sevillano AM, Yuste C, Gutierrez E, Praga M, Egido J, Moreno JA. CD163-Macrophages Are Involved in Rhabdomyolysis-Induced Kidney Injury and May Be Detected by MRI with Targeted Gold-Coated Iron Oxide Nanoparticles. Theranostics 2016; 6(6): 896914 DOI: $\underline{10.7150 / \text { thno.14915 }}$

42 Wang S, Zhang C, Li J, Niyazi S, Zheng L, Xu M, Rong R, Yang C, Zhu T. Erythropoietin protects against rhabdomyolysis-induced acute kidney injury by modulating macrophage polarization. Cell Death Dis 2017; 8(4): e2725 DOI: $10.1038 /$ cddis.2017.104

43 Lee JH, Kam EH, Kim SY, Cheon SY, Kim EJ, Chung S, Jeong JH, Koo BN. Erythropoietin Attenuates Postoperative Cognitive Dysfunction by Shifting Macrophage Activation toward the M2 Phenotype. Front Pharmacol 2017; 8: 839 DOI: 10.3389/fphar.2017.00839

44 Broxmeyer HE. Erythropoietin surprises: an immune saga. Immunity 2011; 34(1): 6-7 DOI: 10.1016/j.immuni.2011.01.004

45 Riehle KJ, Hoagland V, Benz W, Campbell JS, Liggitt DH, Langdale LA. Hepatocellular heme oxygenase-1: a potential mechanism of erythropoietin-mediated protection after liver ischemia-reperfusion injury. Shock 2014; 42(5): 424-431 DOI: 10.1097/SHK.0000000000000231

46 Genc K, Egrilmez MY, Genc S. Erythropoietin induces nuclear translocation of Nrf2 and heme oxygenase-1 expression in SH-SY5Y cells. Cell Biochem Funct 2010; 28(3): 197-201 DOI: $10.1002 / \mathrm{cbf} .1639$

47 Diaz Z, Assaraf MI, Miller WH, Jr., Schipper HM. Astroglial cytoprotection by erythropoietin pre-conditioning: implications 
for ischemic and degenerative CNS disorders. J Neurochem 2005; 93(2): 392-402 DOI: 10.1111/j.1471-4159.2005.03038.x

48 Calo LA, Stanic L, Davis PA, Pagnin E, Munaretto G, Fusaro M, Landini S, Semplicini A, Piccoli A. Effect of epoetin on HO-1 mRNA level and plasma antioxidants in hemodialysis patients. Int J Clin Pharmacol Ther 2003; 41(5): 187-192

49 Katavetin P, Tungsanga K, Eiam-Ong S, Nangaku M. Antioxidative effects of erythropoietin. Kidney Int Suppl 2007(107): S10-15 DOI: $10.1038 /$ sj.ki.5002482

$50 \mathrm{Tu} \mathrm{TH}$, Joe Y, Choi HS, Chung HT, Yu R. Induction of heme oxygenase-1 with hemin reduces obesity-induced adipose tissue inflammation via adipose macrophage phenotype switching. Mediators Inflamm 2014; 2014: 290708 DOI: $10.1155 / 2014 / 290708$

51 Jadhav A, Tiwari S, Lee P, Ndisang JF. The heme oxygenase system selectively enhances the anti-inflammatory macrophage-M2 phenotype, reduces pericardial adiposity, and ameliorated cardiac injury in diabetic cardiomyopathy in Zucker diabetic fatty rats. $\boldsymbol{J}$ Pharmacol Exp Ther 2013; 345(2): 239-249 DOI: $10.1124 /$ jpet.112.200808

52 Choi KM, Kashyap PC, Dutta N, Stoltz GJ, Ordog T, Shea Donohue T, Bauer AJ, Linden DR, Szurszewski JH, Gibbons SJ, Farrugia G. CD206-positive M2 macrophages that express heme oxygenase-1 protect against diabetic gastroparesis in mice. Gastroenterology 2010; 138(7): 2399-2409, 2409 e2391 DOI: 10.1053/j.gastro.2010.02.014
53 Hunter MM, Wang A, Parhar KS, Johnston MJ, Van Rooijen N, Beck PL, McKay DM. In vitro-derived alternatively activated macrophages reduce colonic inflammation in mice. Gastroenterology 2010; 138(4): 13951405 DOI: $10.1053 /$ j.gastro.2009.12.041

54 Orozco LD, Kapturczak MH, Barajas B, Wang $\mathrm{X}$, Weinstein MM, Wong J, Deshane J, Bolisetty S, Shaposhnik Z, Shih DM, Agarwal A, Lusis AJ, Araujo JA. Heme oxygenase-1 expression in macrophages plays a beneficial role in atherosclerosis. Circ Res 2007; 100(12): 1703-1711

DOI:

10.1161/CIRCRESAHA.107.151720

55 Lamon S, Russell AP. The role and regulation of erythropoietin (EPO) and its receptor in skeletal muscle: how much do we really know? Front Physiol 2013; 4: 176 DOI: 10.3389/fphys.2013.00176

56 Lamon S, Zacharewicz E, Stephens AN, Russell AP. EPO-receptor is present in mouse $\mathrm{C} 2 \mathrm{C} 12$ and human primary skeletal muscle cells but EPO does not influence myogenesis. Physiol Rep 2014; 2(3): e00256 DOI: 10.1002/phy2.256

57 Nath KA, Balla G, Vercellotti GM, Balla J, Jacob HS, Levitt MD, Rosenberg ME. Induction of heme oxygenase is a rapid, protective response in rhabdomyolysis in the rat. J Clin Invest 1992; 90(1): 267-270 DOI: $\underline{10.1172 / \mathrm{JCI} 115847}$ 